\title{
Soybean MADS-box gene GmAGL1 promotes flowering via the photoperiod pathway
}

\author{
Xuanrui Zeng ${ }^{1} \mathbb{D}$, Hailun Liu', Hongyang Du', Sujing Wang ${ }^{1}$, Wenming Yang ${ }^{1}$, Yingjun Chi $^{2}$, Jiao Wang ${ }^{1}$,
} Fang Huang ${ }^{1 *}$ and Deyue $\mathrm{Yu}^{1 *}$

\begin{abstract}
Background: The MADS-box transcription factors are an ancient family of genes that regulate numerous physiological and biochemical processes in plants and facilitate the development of floral organs. However, the functions of most of these transcription factors in soybean remain unknown.

Results: In this work, a MADS-box gene, GmAGL1, was overexpressed in soybean. Phenotypic analysis showed that GmAGL1 overexpression not only resulted in early maturation but also promoted flowering and affected petal development. Furthermore, the GmAGL1 was much more effective at promoting flowering under long-day conditions than under short-day conditions. Transcriptome sequencing analysis showed that before flowering, the photoperiod pathway photoreceptor CRY2 and several circadian rhythm genes, such as SPA1, were significantly down-regulated, while some other flowering-promoting circadian genes, such as GI and LHY, and downstream genes related to flower development, such as FT, LEAFY, SEP1, SEP3, FUL, and AP1, were up-regulated compared with the control. Other genes related to the flowering pathway were not noticeably affected.

Conclusions: The findings reported herein indicate that GMAGL1 may promote flowering mainly through the photoperiod pathway. Interestingly, while overexpression of GmAGL1 promoted plant maturity, no reduction in seed production or oil and protein contents was observed.
\end{abstract}

Keywords: MADS-box gene, Flowering, Photoperiod pathway, Transgenic, Soybean

\section{Background}

Flowering is initiated by the transition from a vegetative to a reproductive fate. In most flowering plants, this is an extremely important developmental process because it directly affects successful reproduction. Four major pathways, the photoperiod pathway, vernalization pathway, gibberellic acid (GA)-dependent pathway, and autonomous pathway, have been demonstrated to regulate flowering in Arabidopsis thaliana [36]. These four pathways, either alone or in combination, form a complex network that regulates plant flowering at the appropriate time based on changes in ambient conditions [8]. The four pathways are integrated by downstream target genes,

\footnotetext{
* Correspondence: fhuang@njau.edu.cn; dyyu@njau.edu.cn

${ }^{1}$ National Key Laboratory of Crop Genetics and Germplasm Enhancement, National Center for Soybean Improvement, Nanjing Agricultural University, Nanjing, Jiangsu 210095, China

Full list of author information is available at the end of the article
}

including LEAFY (LFY), FLOWERING LOCUS T (FT) and SUPPRESSOR OF CONSTANS1 (SOC1), with their resulting outcomes conveyed to floral meristem identity genes, such as APETALA 1 (AP1), at the shoot apical meristem (SAM), which triggers the flowering process $[57,58]$.

Photoperiod pathways regulate flowering time by sensing changes in day length. Long-day plants, such as Arabidopsis, exhibit precocious flowering under long-day conditions but delayed flowering or non-flowering under short-day conditions [15]. In contrast, short-day plants, such as soybean and rice, display precocious flowering under short-day conditions but delayed flowering or non-flowering under long-day conditions [20]. Briefly, photoreceptors receive a light signal and transduce it to genes that are linked to the plant's biological clock to "turn on" the circadian rhythm, which is then induced together with downstream floral organ 
development and flowering-time-related genes to regulate flowering time [15].

Though the genetic processes regulating flowering in Arabidopsis are well known, much less is understood about these networks in other species, especially for shortday plants with a photoperiod pathway that may differ from long-day plants [17]. Soybean (Glycine max [L.] Merr.) is a typical short-day plant and one of the most important commercial oil crops to the world economy, providing approximately $69 \%$ of the dietary protein and $30 \%$ of the oil consumed by humans [1]. Its reproductive growth directly affects seed yield and quality. Therefore, unravelling the genetic mechanisms underlying the regulation of flowering is of great significance to improve seed production and to study ecological adaptability in soybean. A classical genetics study revealed that ten genes, the genes E1-E9 and J, were closely related to flowering and plant maturity in soybean [25]. Some of them have been mapped and found to be functionally involved in the photoperiod pathway and the regulation of soybean flowering $[26,31,33,51,55,58]$.

Genes in the MADS-box family of transcription factors (TFs) also play important roles in reproductive growth and development. They participate in the early steps of floral meristem development to specify the identity of a primordial floral organ later in flower development in A. thaliana [5]. However, few studies have examined soybean MADSbox genes [65]. Our group previously detected a high expression level of the AG-like MADS-box gene GmAGL1 in a soybean flower cDNA microarray. Heterologous expression of GmAGL1 in A. thaliana was shown to affect floral development and exhibit a premature phenotype [9].

Although studies have found that many genes are involved in Arabidopsis flowering and flower development processes [5], it has also been found that several genes do not play exactly the same role in Arabidopsis as in other crops [17]. Although the genome-wide expression of soybean MADS genes has been analysed [10, 47], soybean MADS-box genes have been much less investigated, with only a few genes functionally studied in soybeans [43]. The specific functions of most of these genes are still unknown. Because the molecular mechanism underlying GmAGL1 remains unclear and the function of this gene in soybean has not been well studied, it is of interest to investigate the function of GmAGL1 and elucidate its regulatory mechanism in soybean. Consequently, we transferred this gene into soybean in the present analysis and found that GmAGL1 might be involved in plant maturation during the transition from the vegetative to the reproductive state.

\section{Results}

\section{GmAGL1 expression patterns differ in transgenic plants} The MADS-box gene GmAGL1 (GenBank accession number: AW433203) was transformed into the soybean cultivar 'Jack', resulting in several GmAGL1 overexpression (GmAGL1-OX) transgenic plants. Expression of GmAGL1 was significantly elevated in most transgenic plants compared with that in wild-type (WT) 'Jack' (Additional file 1: Figure S1). Homozygous transgenic plants from two GmAGL1-OX lines (GmAGL1-OX line 1 and GmAGL1OX line 5) were screened and used for further study.

To investigate the tissue expression patterns of GmAGL1 in the control (WT Jack) and transgenic plants, real-time PCR was performed in roots, stems, leaves, flowers, pods and shoot apical meristem (SAM). The results showed that the expression of GmAGL1 in both GmAGL1-OX transgenic lines was significantly higher than that in WT among all the tested tissues (Fig. 1a). In both transgenic lines, among all the examined tissues, expression of GmAGL1 was highest in SAM. GmAGL1 expression in SAM of WT and transgenic plants was then examined from the $\mathrm{VC}$ (cotyledon stage) to the R1 (the beginning of flowering) stage. The expression of GmAGL1 in SAM was significantly higher in transgenic plants than in WT during the six investigated stages (Fig. 1b).

To determine whether the insertion sites would affect the expression of the GmAGL1 gene, thermal asymmetric interlaced PCR (TAIL-PCR) was used to map the transgene insertion sites in the transgenic lines (Additional file 1: Figure S2). Interestingly, the transgene insertion sites of these two transgenic lines were only in non-coding regions; that in GmAGL1-OX line 1 was located in the non-coding region between the genes Glyma13G31150 and Glyma13G31160, and that in GmAGL1-OX line 5 was located in the non-coding region on chromosome 20, between Glyma.20G049600 and Glyma.20G049700 (these two gene models are present only in the current Wm82.a2 assembly, annotation version 1 set).

\section{Flowering and plant maturity in transgenic lines overexpressing GmAGL1}

Early flowering and prematurity were observed in GmAGL1-OX transgenic plants.

The flowering time was measured using the measure of days after sowing (DAS) to the appearance of the first flower at any node of the main stem (R1 stage). In the field, WT Jack plants started flowering at $39.4 \pm 0.49$ DAS, and florescence ended at 58.6 \pm 1.17 DAS, with a florescence duration of $19.2 \pm 1.25$ days (Table 1). Transgenic lines 1 and 5 started flowering at $36.7 \pm 0.49$ and $36.5 \pm 0.49$ DAS, respectively, approximately 3 days earlier than the WT and other lines. The whole florescence duration was $16.2 \pm 0.75$ and $16.1 \pm 0.70$ days in transgenic lines 1 and 5 , respectively, approximately 3 days shorter than in the WT. 

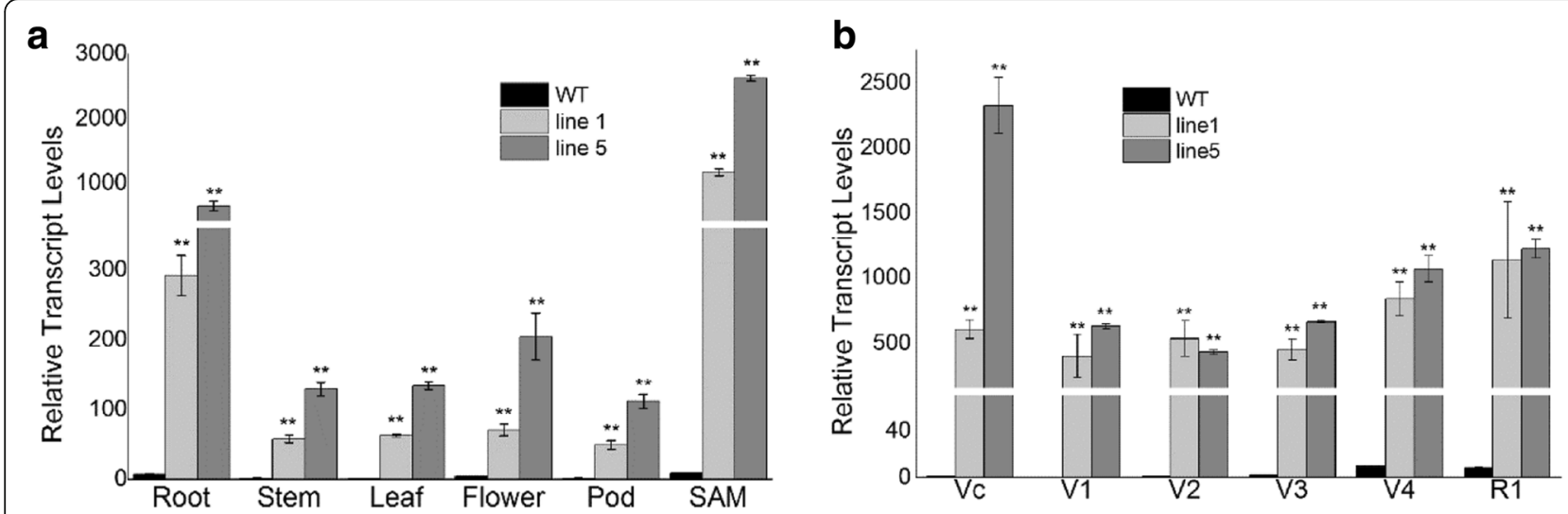

Fig. 1 Expression patterns of the GmAGL1 gene. a Gene expression of GmAGL1 in various tissues of the five homozygous transgenic lines and WT. The T2 generations of the two homozygous transgenic lines GmAGL1-OX lines 1 and 5 and WT were cultured in soil. RNA was extracted from roots, stems, leaves, and shoot apical meristems (SAMs) of 20-day-old seedlings. RNA was extracted from flowers and pods of 50-day-old seedlings. WT leaves were used as a control (relative expression of 1) to compare the relative expression of other samples. $\mathbf{b}$ Gene expression of GmAGL1 in the V0-R1 period in five homozygous transgenic plant SAMs. The T2 generations of the five homozygous transgenic lines, GmAGL 1-OX lines 1 and 5, and WT were cultured in soil. RNA of SAMs was extracted from plants at the VC to R1 stages. VC (cotyledon) stage: single leaf half expanded, leaf margin separated; V1 (one-node) stage: single leaf fully grown, leaf margin of the first compound leaf separated; V2 (two-node) stage: the first compound leaf above the single leaf fully grown; V3 (three-node) stage: including the single leaf, three leaves on the main stem fully grown; V4 (four-node) stage: including the single leaf, four leaves on the main stem fully grown; R1 stage (the beginning of flowering): a flower is open at any position on the main stem. SAMs of WT-VC were used as a control (relative expression of 1) to compare relative expression in the other samples. GmAGL1 transcript levels were determined by qRT-PCR. The a-Tubulin gene was amplified as an internal control to normalize all the data. Transcript levels were calculated using the $2^{-\Delta \Delta C t}$ formula to measure the expression levels relative to GMAGL1. Data are presented as the means of three biological replicates, and error bars indicate SDs. Asterisks indicate a significant difference between the WT and transgenic plants $\left.{ }^{* *} P<0.01,{ }^{*} P<0.05\right)$

In addition to the differences in growth periods, the development of floral organs in transgenic plants was also altered. For instance, the petals of transgenic plants were not fully expanded until the soybeans were in pods and were smaller than in the WT control (Fig. 2a, b). Through anatomical observation of the floral organs at the time of flowering, the opening angle of the vexillum and wing petal was found to be smaller in transgenic plants than in WT, resulting in petals that could not fully expand. In addition to petals, the pistils and stamens of transgenic plants were also slightly smaller than in the WT control (Fig. 2c). Excluding the homozygous lines 1 and 5, the other heterozygous transgenic plants in the field undergoing the early generation also presented early flowering and incompletely expanded petals (Additional file 1: Figure S3), and they were also precocious.

Moreover, the transgenic plants showed prematurity. For example, while WT plants were still in the late filling period (R6), the leaves of transgenic plants had turned yellow and entered the early mature stage (R7) (Fig. 2d). Throughout the growing season, transgenic plants showed an average prematurity of 5-7 days compared with WT plants.

\section{Transgenic plant flowering under long-day/short-day conditions}

As a typical short-day plant, the flowering time of soybean is strongly influenced by day length. To further investigate the effect of day length on GmAGL1, 7-day-old seedlings of WT and transgenic plants under 14/10-h light/dark conditions were transferred to short-day (SD, 12/12-h light/dark) or long-day (LD, 16/8-h light/dark) conditions and grown until flowering. The flowering time data showed that transgenic plants flowered precociously under both SD and LD conditions (Fig. 3). Under SD conditions, transgenic plants started flowering at $38.9 \pm 0.70$ and $38.6 \pm 0.66$ DAS, respectively, which was significantly earlier than WT (42.0 \pm 0.77 DAS). However, all the soybean plants flowered later

Table 1 Flowering time and duration of field-grown transgenic and WT soybean lines

\begin{tabular}{llll}
\hline Plant lines & $\begin{array}{l}\text { Start flowering } \\
\text { (DAS) }\end{array}$ & $\begin{array}{l}\text { End flowering } \\
\text { (DAS) }\end{array}$ & $\begin{array}{l}\text { Florescence duration } \\
\text { (Days) }\end{array}$ \\
\hline GmAGL1-OX line 1 & $36.7 \pm 0.49 \mathrm{~B} \mathrm{~b}$ & $52.9 \pm 0.75 \mathrm{~B} \mathrm{~b}$ & $16.2 \pm 0.75 \mathrm{~B} \mathrm{~b}$ \\
GmAGL1-OX line 5 & $36.5 \pm 0.49 \mathrm{~B} \mathrm{~b}$ & $52.6 \pm 0.49 \mathrm{~B} \mathrm{~b}$ & $16.1 \pm 0.70 \mathrm{~B} \mathrm{~b}$ \\
WT & $39.4 \pm 0.49 \mathrm{~A} \mathrm{a}$ & $58.6 \pm 1.17 \mathrm{~A} \mathrm{a}$ & $19.2 \pm 1.25 \mathrm{~A} \mathrm{a}$ \\
\hline
\end{tabular}

Data are shown as average of ten plants \pm SD; different capital letters indicate a significant difference at the 0.01 level, and different lowercase letters indicate a significant difference at the 0.05 level 


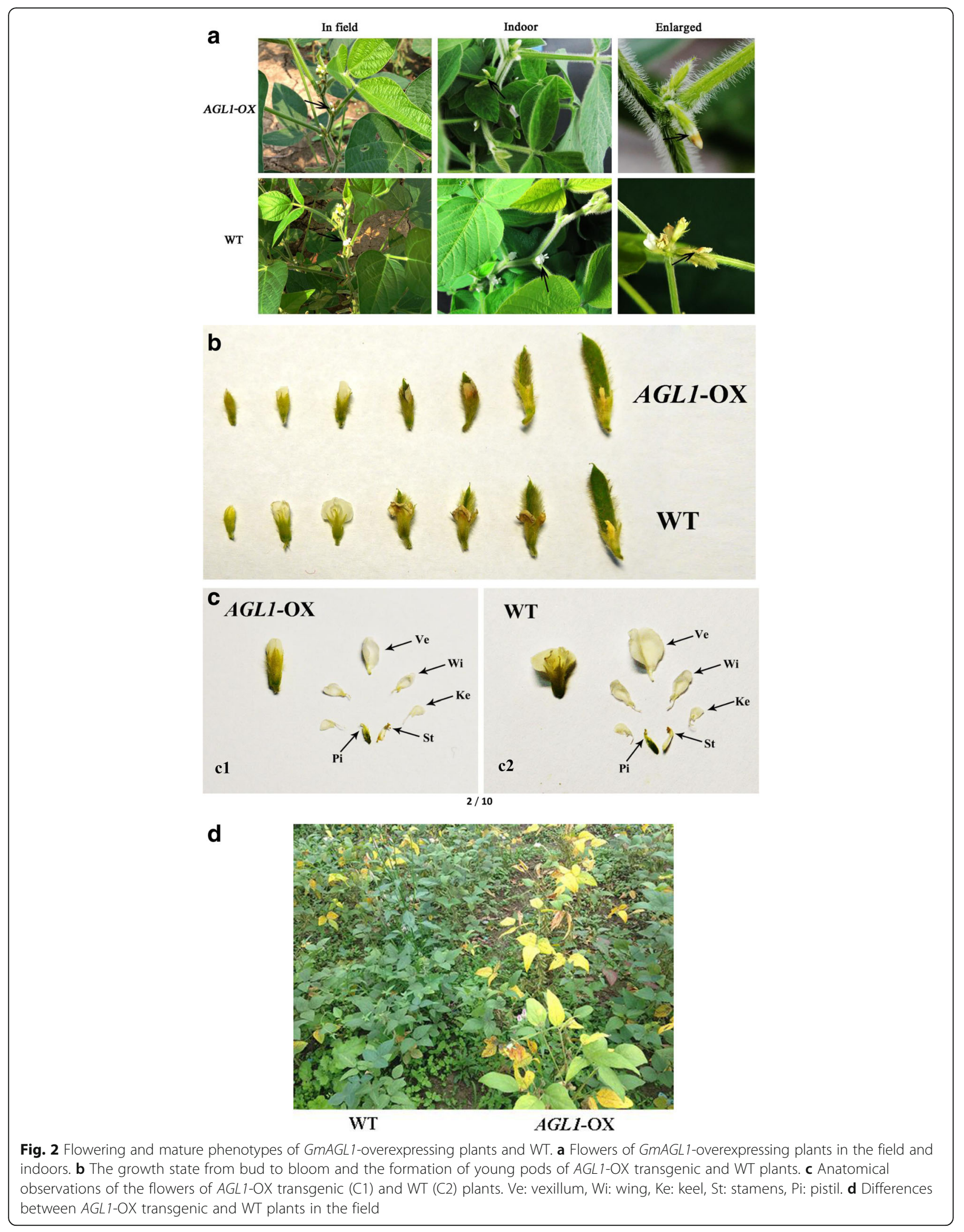




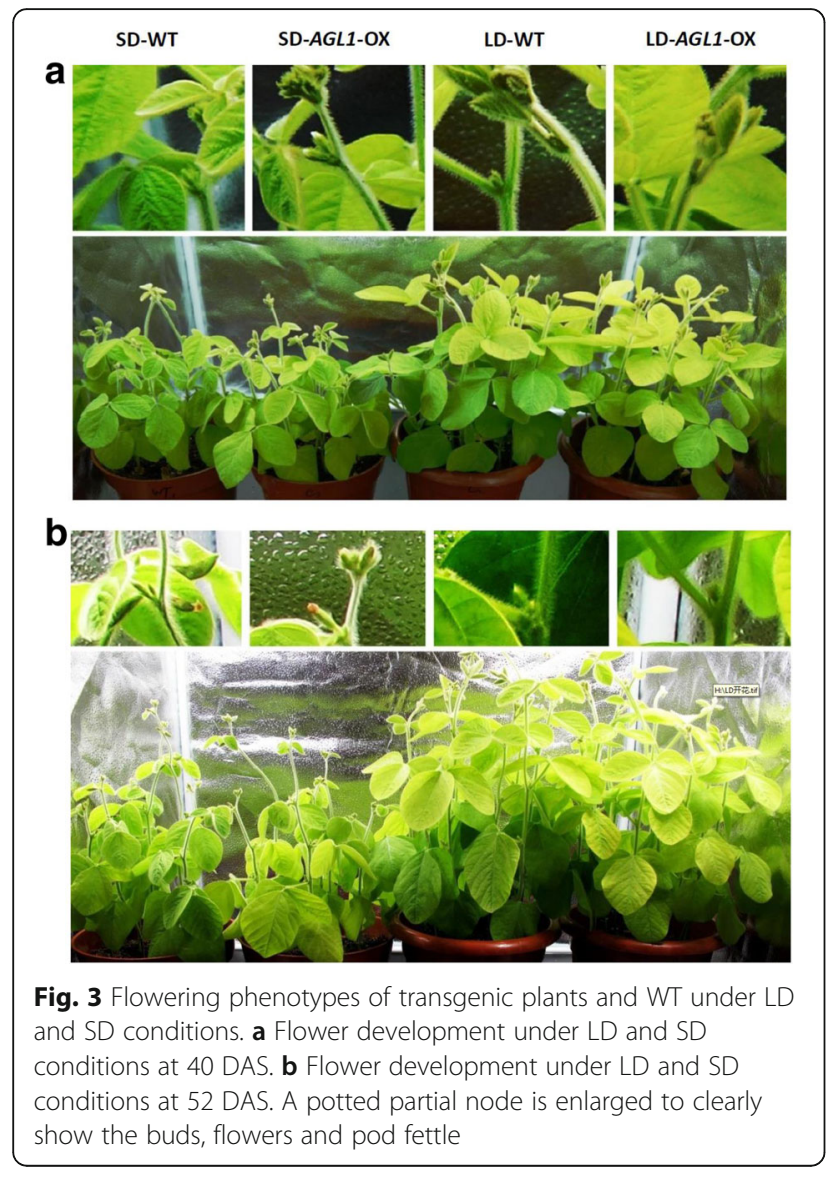

under LD than under SD conditions. Under LD conditions, transgenic line 1 and line 5 plants started flowering at 45.8 \pm 0.75 DAS and $45.7 \pm 0.64$ DAS, respectively, which was also significantly earlier than in WT $(53.6 \pm 0.66$ DAS $)$. In contrast to the WT control, the early flowering phenomenon observed in transgenic plants was more significant under LD (approximately eight days) than under SD conditions (approximately three days) (Table 2).

\section{Agronomic traits of transgenic soybean plants}

To explore the effect of the GmAGL1 gene on agronomic traits, WT Jack plants and homozygous transgenic plants

Table 2 Flowering time of transgenic and WT soybean lines under short-day and long-day conditions

\begin{tabular}{lll}
\hline & Plant lines & Flowering time (DAS) \\
\hline Short-day & WT & $42.0 \pm 0.77 \mathrm{C} \mathrm{c}$ \\
& GmAGL1-OX line 1 & $38.9 \pm 0.70 \mathrm{D} \mathrm{d}$ \\
GmAGL1-OX line 5 & $38.6 \pm 0.66 \mathrm{D} \mathrm{d}$ \\
& WT & $53.6 \pm 0.66 \mathrm{~A} \mathrm{a}$ \\
& GmAGL1-OX line 1 & $45.8 \pm 0.75 \mathrm{~B} \mathrm{~b}$ \\
& GmAGL1-OX line 5 & $45.7 \pm 0.64 \mathrm{~B} \mathrm{~b}$ \\
\hline
\end{tabular}

Data are shown as average of ten plants $\pm \mathrm{SD}$; different capital letters indicate a significant difference at the 0.01 level, and different lowercase letters indicate a significant difference at the 0.05 level in the T3/T4 (2015) and T4/T5 (2016) generations were cultured in the field and harvested in late September. No differences between transgenic and WT plants were observed for node number of the main stem, branch number per plant, seed kernel weight, total pods, total seeds, seed yield per plant, or cracked pod rate (Table 3). Regarding plant height, only the T3 (2015) generation of transgenic line 5 was dramatically shorter than the WT, whereas the transgenic line 5 plants in the T4 (2015) and T4/T5 (2016) generations showed no significant differences from WT in plant height. All the plants in transgenic line 1 also showed no significant differences from WT. GmAGL1 may not greatly impact these agronomic traits.

Protein and oil contents are the most abundant constituents in soybean seeds, and they are also important indicators of soybean quality. By using near infrared spectroscopy, the protein, but not the oil, contents of transgenic lines in both 2015 and 2016 were found to have significantly increased (Fig. 4a) compared with WT (Fig. 4b).

\section{Transcriptomic differences between WT and GmAGL1- overexpressing transgenic plants}

To investigate how the genetic programming is deployed in transgenic plants, Illumina RNA sequencing was applied to SAM tissues from three growth stages (VC, V4 and R1) in both transgenic and WT plants (Fig. 5a, b).

The transcriptome analysis data revealed a total of 4401 genes with significant differences in expression between the transgenic line and the WT. Among these 4401 differentially expressed genes (DEGs), 1184 genes were from the VC stage, 2302 from the V4 stage, and 1778 from the R1 stage (Fig. 5a). A total of 106 genes showed altered expressed in GmAGL1-OX plants in all three stages. Among them, GmAGL1 showed the most significant changes in all three stages and was expressed at levels more than 10 times higher in transgenic plants than in controls (Additional file 2).

Cluster analysis of DEGs indicated that the gene expression pattern of transgenic plants $(\mathrm{VC})$ was more similar to WT (VC) in the VC stage than in other stages (Fig. 5b). However, in the V4 and R1 stages, the expression patterns of DEGs in WT and transgenic plants were both more similar to the adjacent growth stages. Moreover, the expression pattern of DEGs in transgenic plants at V4 was more similar to WT at R1 than to WT at V4. That is, the gene expression pattern of transgenic plants in the flowering preparation state (V4) was more similar to WT plants in the flowering stage (R1), and the transgenic plants therefore exhibited earlier flowering than the WT controls.

KEGG (Kyoto Encyclopaedia of Genes and Genomes) pathway analysis of the DEGs revealed that the circadian rhythm pathway was one of the DEG-enriched pathways in the V4 and R1 stages (Fig. 5c). 
Table 3 Descriptive statistics for agronomic traits of transgenic and WT soybean lines

\begin{tabular}{llllllllll}
\hline & & PH & NM & BR & TP & TS & SY (g) & SW (g) & CR (\%) \\
\hline 2015 & WT & $44.93 \pm 5.46$ & $15.80 \pm 1.40$ & $2.50 \pm 1.20$ & $46.00 \pm 12.64$ & $80.00 \pm 27.95$ & $8.67 \pm 2.99$ & $11.19 \pm 2.30$ & $0.03 \pm 0.02$ \\
& line 1 (T3) & $46.00 \pm 6.02$ & $15.90 \pm 0.94$ & $1.80 \pm 0.87$ & $41.70 \pm 5.44$ & $65.70 \pm 17.65$ & $7.18 \pm 2.02$ & $11.41 \pm 3.33$ & $0.01 \pm 0.02$ \\
& line 5 (T3) & $36.19 \pm 2.15 * *$ & $15.75 \pm 0.97$ & $2.00 \pm 0.50$ & $45.88 \pm 9.61$ & $65.88 \pm 17.73$ & $7.97 \pm 1.75$ & $12.35 \pm 1.31$ & $0.01 \pm 0.02$ \\
& line 1 (T4) & $40.78 \pm 5.10$ & $15.00 \pm 1.00$ & $2.88 \pm 1.05$ & $58.25 \pm 10.23$ & $108.50 \pm 25.68$ & $12.45 \pm 2.87$ & $11.63 \pm 1.89$ & $0.02 \pm 0.01$ \\
& line 5 (T4) & $43.76 \pm 4.48$ & $15.70 \pm 0.78$ & $2.20 \pm 1.17$ & $47.60 \pm 7.17$ & $83.00 \pm 13.32$ & $10.42 \pm 2.12$ & $12.56 \pm 1.57$ & $0.01 \pm 0.02$ \\
2016 & WT & $51.83 \pm 5.81$ & $15.80 \pm 1.08$ & $1.30 \pm 0.90$ & $23.50 \pm 5.16$ & $37.86 \pm 6.88$ & $4.07 \pm 0.43$ & $10.67 \pm 1.10$ & $2.21 \pm 0.02$ \\
& line 1 (T4) & $52.90 \pm 5.60$ & $15.60 \pm 1.02$ & $1.60 \pm 0.80$ & $28.50 \pm 8.05$ & $46.30 \pm 12.20$ & $4.88 \pm 0.93$ & $10.78 \pm 0.95$ & $1.93 \pm 0.02$ \\
& line 5 (T4) & $52.40 \pm 6.45$ & $15.80 \pm 1.40$ & $1.30 \pm 0.90$ & $23.90 \pm 5.26$ & $38.50 \pm 7.35$ & $4.01 \pm 0.54$ & $10.73 \pm 1.10$ & $2.21 \pm 0.02$ \\
& line 1 (T5) & $51.60 \pm 8.24$ & $15.30 \pm 0.90$ & $1.40 \pm 0.92$ & $25.80 \pm 6.24$ & $43.80 \pm 7.91$ & $4.59 \pm 0.58$ & $10.64 \pm 1.01$ & $1.95 \pm 0.02$ \\
& line 5 (T5) & $50.10 \pm 6.28$ & $15.90 \pm 1.30$ & $1.30 \pm 0.78$ & $21.50 \pm 4.10$ & $35.00 \pm 4.38$ & $3.67 \pm 0.28$ & $10.61 \pm 1.01$ & $1.93 \pm 0.02$
\end{tabular}

Data for plant height (PH), nodes of the main stem (NM), branches (BR), total pods per plant (TP), total seeds per plant (TS), seed yield per plant (SY, measured in $\mathrm{g})$, seed kernel weight (SW, measured in $\mathrm{g}$ ) and cracked pod rate (CR measured in \%) are shown as average of plants \pm SD. Asterisks indicate a significant difference between the control and transgenic plants in the same year (** $P<0.01$ )

\section{Circadian rhythm genes presented significant differences} in transgenic plants

By analysing the expression of genes related to soybean flowering and maturity regulation in transgenic plants, the expression levels of the $E 2$ gene GmGIa, together with the E7 gene GmFT2a and its orthologue GmFT5a, were found to be significantly altered in both transgenic lines compared with the WT control before flowering (Fig. 6). Soybean E2 is orthologous to the A. thaliana GIGANTEA (GI) gene, which is a critical gene in the circadian rhythm [55]. GmFT2a and GmFT5a are orthologous to AtFT, which is also a circadian rhythm gene and plays an important role in the regulation of flowering [8].

Subsequently, we investigated the transcription of other circadian rhythm genes in the transcriptome and showed that most of the transcripts associated with soybean circadian rhythm and/or their orthologues differed significantly between transgenic plants and WT (soybean circadian rhythm genes were found online at http://www.genome.jp/kegg-bin/show_pathway?gmx047 12 soybean circadian rhythm, Fig. 7).

\section{Photoperiod pathway genes presented significant differences between transgenic and control plants}

Photoreceptors and circadian clocks are mechanisms for sensing and responding to the light environment via photoperiod pathways [27]. Thus, we examined the transcription of all photoperiod pathway-related genes, including photoreceptors, circadian rhythm genes and downstream flower development regulatory genes. The results showed that most of the genes associated with the photoperiod pathway in GmAGL1-OX line 5 were
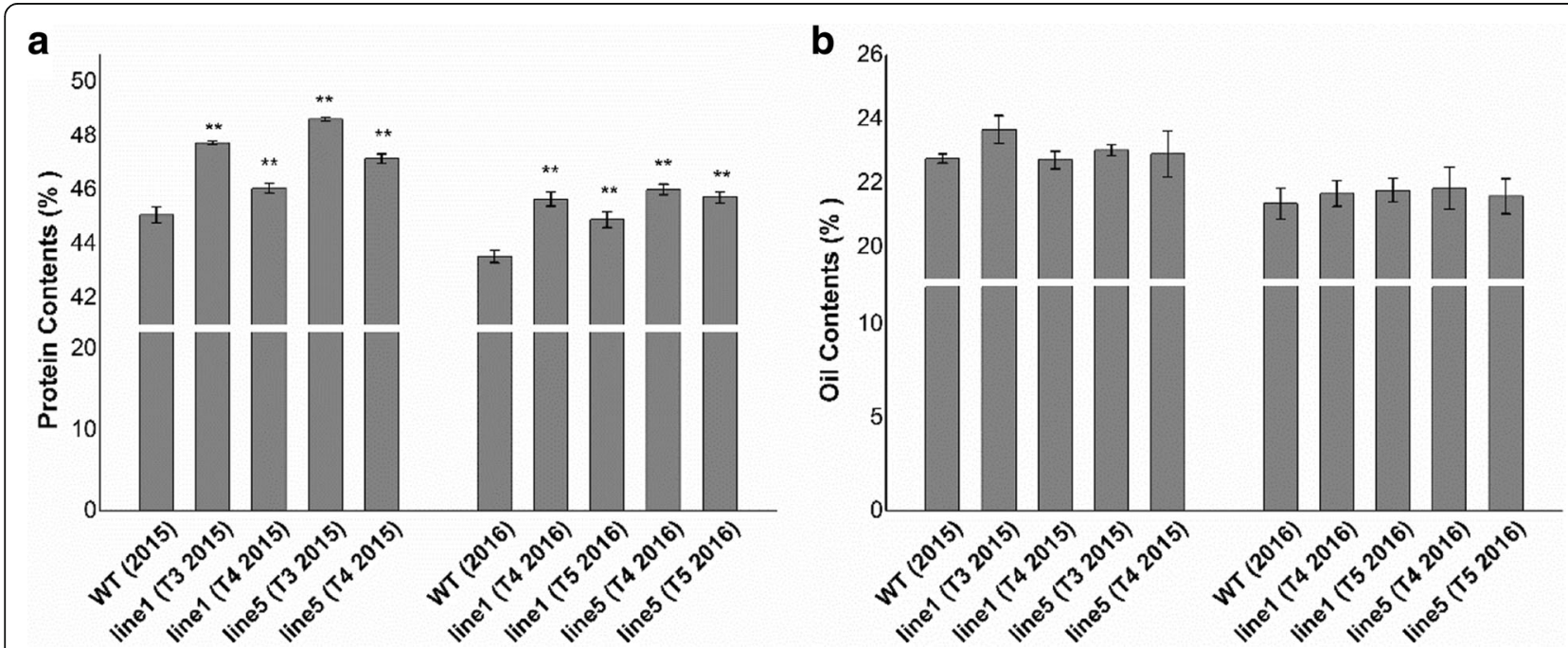

Fig. 4 Protein and oil contents of transgenic soybean seeds. a The percentages of protein contents of transgenic lines and WT in the T3, T4 and T5 generations. $\mathbf{b}$ The percentages of oil contents of transgenic lines and WT in the T3, T4 and T5 generations. Asterisks indicate a significant difference between WT and transgenic plants $\left.{ }^{* *} P<0.01\right)$ 
a

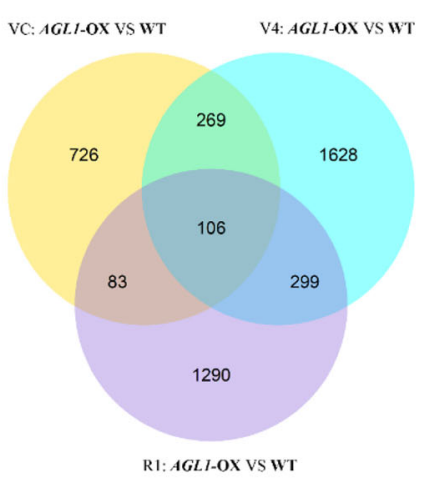

b Cluster analysis of differentially expressed genes

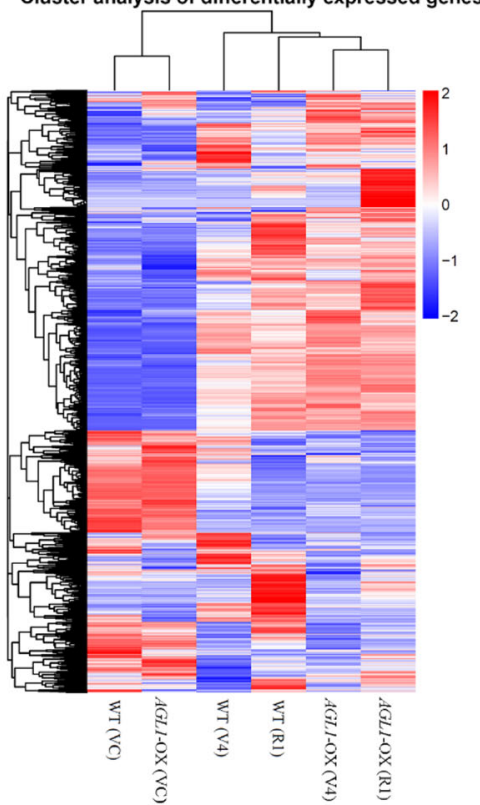

C
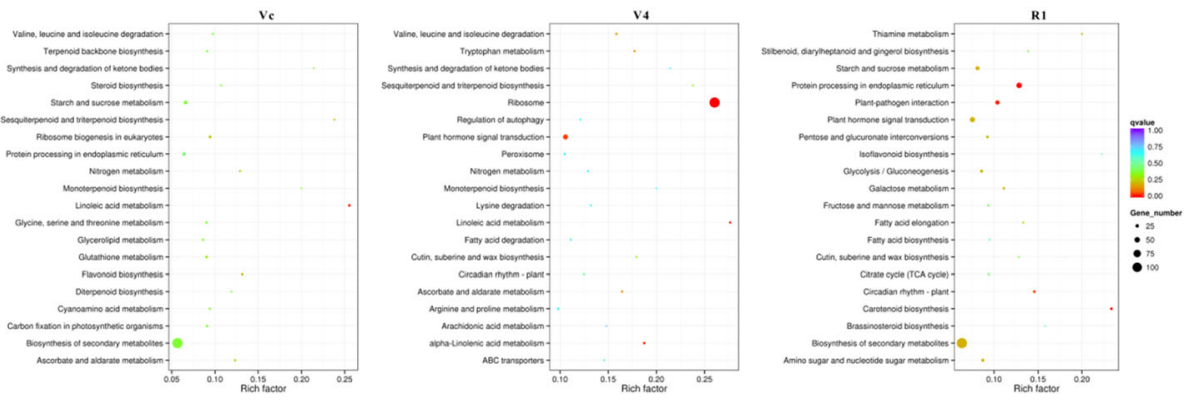

Fig. 5 Transcriptome sequencing and cluster analysis of differentially expressed genes. a Venn diagram showing the number of DEGs between AGL1-OX transgenic and WT plants in the VC, V4 and R1 stages. $\mathbf{b}$ Heat cluster of DEGs between AGL1-OX transgenic and WT plants in the VC, V4 and R1 stages. c Scatterplot showing the most enriched KEGG pathways of DEGs between AGL 1-OX transgenic and WT plants in the VC, V4 and R1 stages. The Y-axis shows the most enriched KEGG pathways, and the X-axis shows the enrichment factor. The sizes of the plots indicate the number of DEGs in the pathway, and the colours of the plots indicate the Q-value of each pathway

significantly differentially expressed compared with WT (Fig. 8).

SAM transcriptome sequencing data revealed that in the early vegetative stage $\mathrm{VC}$, a total of 27 photoperiod pathwayrelated genes in transgenic plants presented differences in expression in comparison to WT. Most of the DEGs were down-regulated in the transgenic plants, whereas only four genes were up-regulated. The most highly up-regulated DEGs were the orthologues of SEPALLATA 1 (SEP1) and SEPALLATA3 (SEP3), which are required for the development of petals, stamens and carpels [42] (Fig. 8a).

At the V4 stage, transgenic plants showed downregulation of 13 genes involved in the photoperiod pathway and up-regulation of 26 photoperiod genes compared with WT (Fig. 8b). The photoreceptor genes $C R Y 2 a$ and $C R Y 2 c$ and circadian rhythm genes ELF3, SUPPRESSOR OF PHYA-105 1 s (SPA1s), FLAVIN-
BINDING KELCH REPEAT F Box 1 s (FKF1s), CRYPTOCHROME-INTERACTING BASIC-HELIX-LOOP-HELIX (CIB1), CSNK2A, and AS1 homologues, together with the flowering regulatory genes TEMPRANILLO $1 \mathrm{~s}$ (TEM1s) and SHORT VEGETATIVE PHASE (SVP) homologues showed slightly decreased expression in transgenic plants. Other circadian genes that showed increased expression included PIF3s, CHSs, CONSTITUTIVE PHOTOMORPHOGENIC1 (COP1), LHYs and GIs, together with the flowering and flower developmentrelated genes $F T$ orthologous gene FT2a, LFYs, FRUITFULL (FUL), AP1s, and SEP3s. Among them, the genes showing the greatest differences in expression were the critical flowering-promoted gene $F T 2 a$ and the flower development-related gene SEP3.

During flowering (R1 period), 26 genes related to the photoperiod pathway showed down-regulated expression 


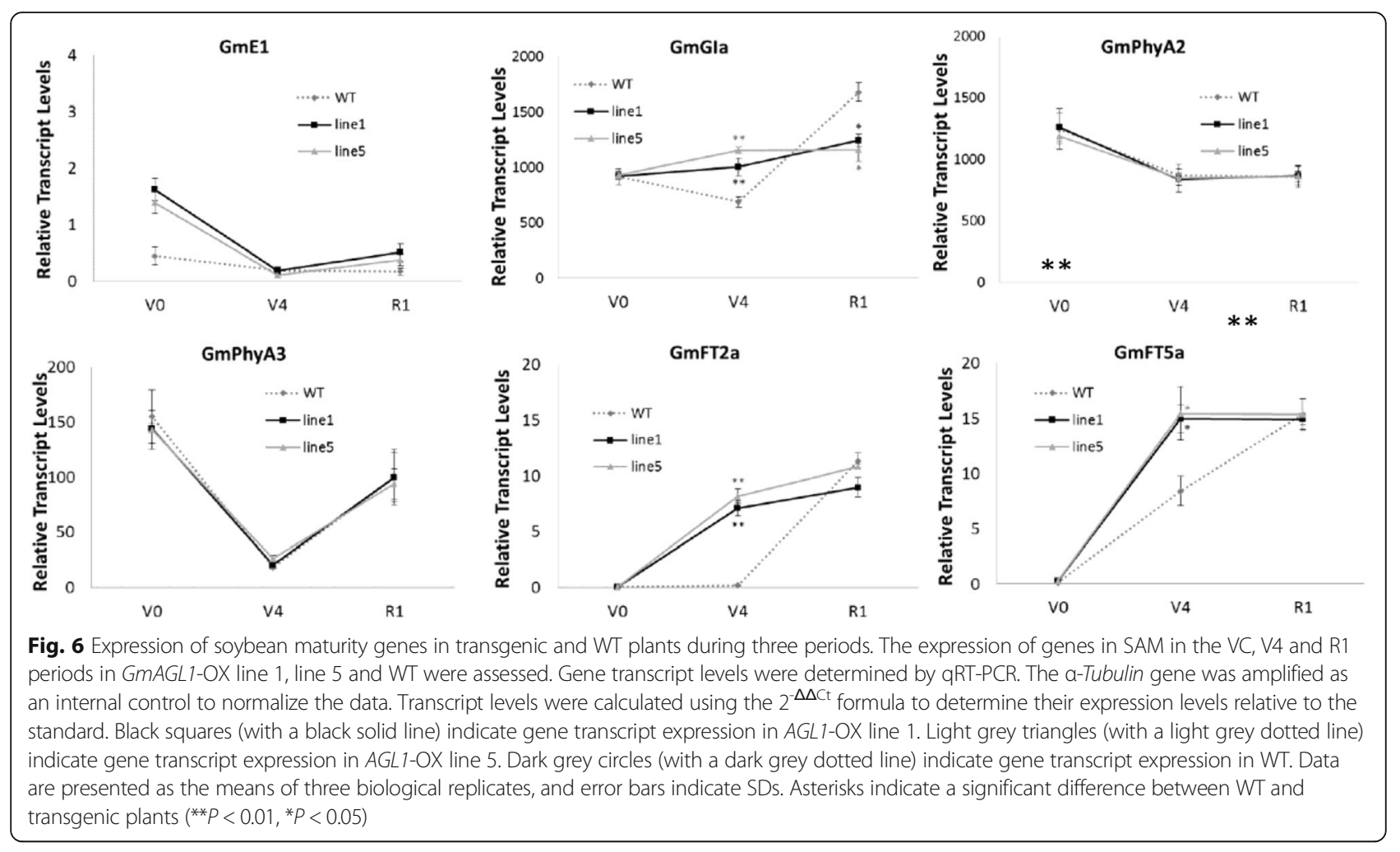

CIRCADIAN RHYTHM - PLANT

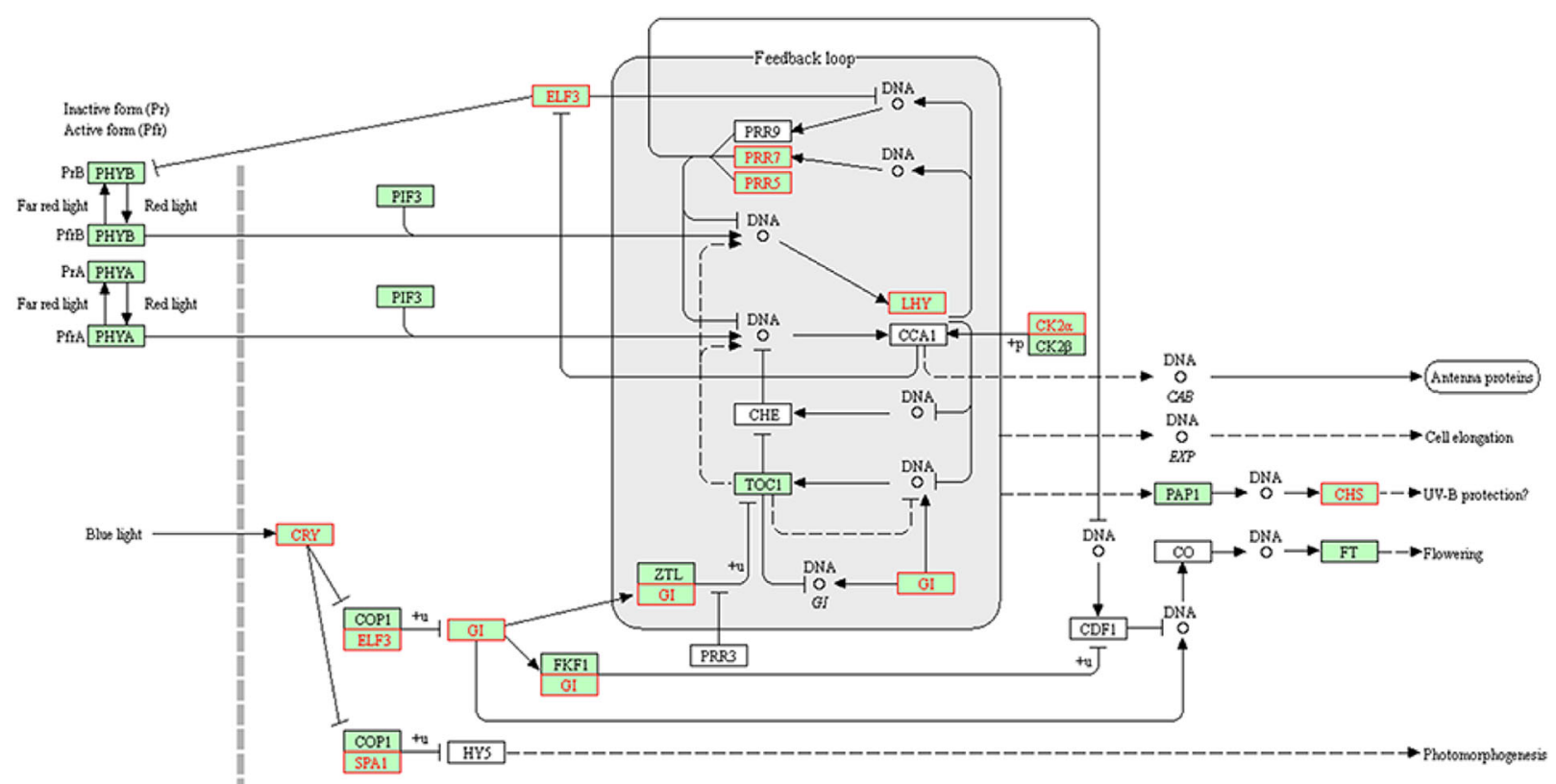

Fig. 7 Differences in expression of circadian rhythm genes between WT and AGL1-OX transgenic plants. The image shows the soybean circadian clock genes in the intact biological network (http://www.genome.jp/kegg-bin/show_pathway?gmx04712). The white box indicates an Arabidopsis circadian clock gene with no homologues in soybean. The red box indicates a DEG between transgenic and WT plants. The black box indicates soybean gene expression that was not markedly changed in transgenic plants 

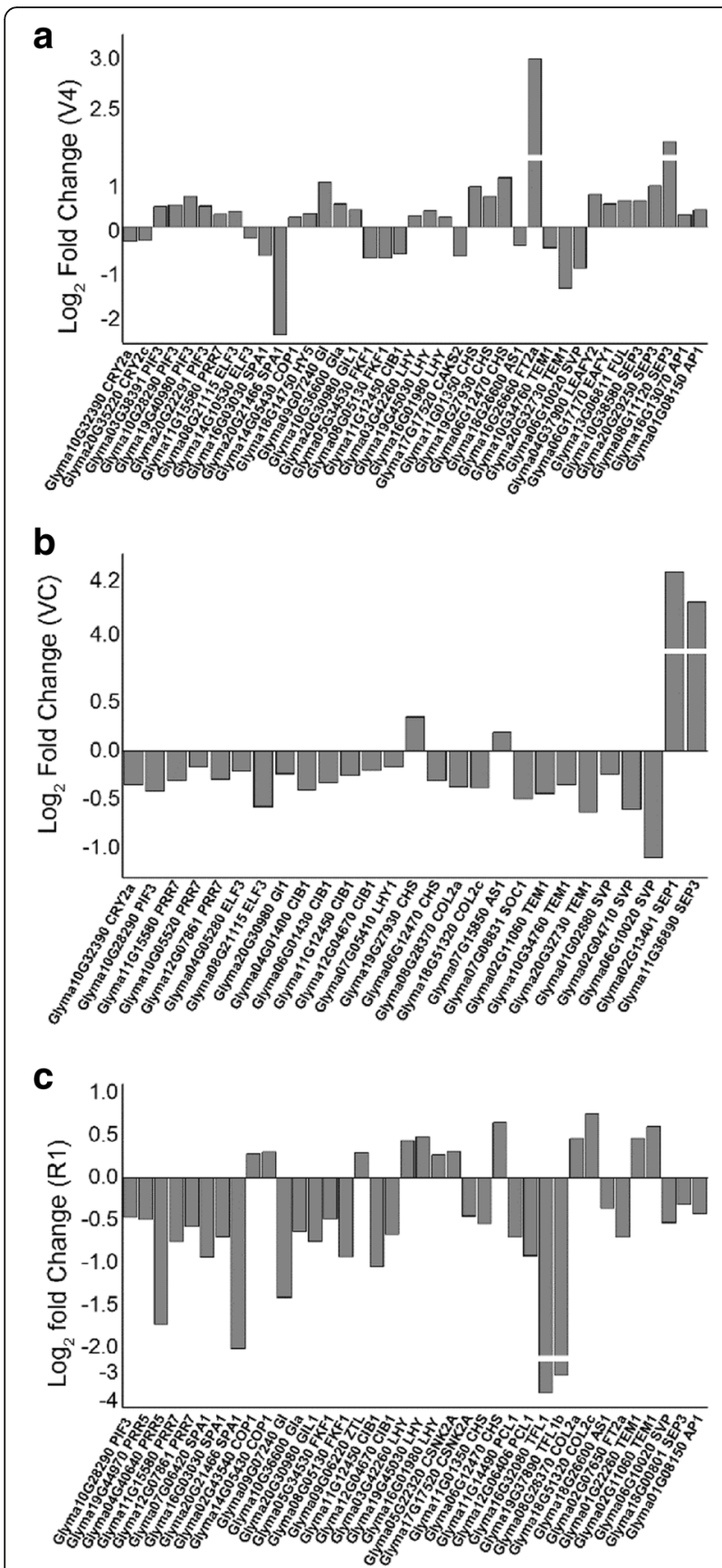

Fig. 8 Transcripts associated with the photoperiod pathway that were regulated in AGL1-OX line 5. Photoperiod pathway-related genes showed alterations based on transcriptome sequencing of the VC (a), V4 (b) and R1(c) stages. The X-axis lists the IDs of genes that were significantly regulated in transgenic plants and their corresponding homologues in Arabidopsis. The $Y$-axis shows the $\log _{2}$ fold change in transcription between the transgenic plants and WT plants

in transgenic plants compared with WT (Fig. 8c). Most of the circadian rhythm genes, including the GIs, were up-regulated once in the V4 stage and then downregulated after flowering. The flowering regulatory genes PCLs, AS1, TFL1s, FT2a, SVP, SEP3, and AP1 were also down-regulated in transgenic plants. Among them, the most differentially expressed genes were two orthologues of TFL1, which regulate inflorescence meristem development [46]. In contrast, 12 genes were slightly up-regulated.

During the transition from vegetative growth to reproductive growth, the expression levels of photoreceptor genes and most circadian rhythm genes seemed to be lower in transgenic than WT plants. In transgenic plants, the circadian rhythm and flower development genes, including GIs, FT2a, SEPs, and AP1, showed increased transcript levels when ready to blossom, followed by a sharp decrease after flowering.

\section{Gene expression changes in other flowering regulatory pathways}

The main flowering pathways in A. thaliana are the photoperiod, vernalization, GA and autonomous pathways. Investigating gene expression in other pathways, in addition to the photoperiod pathway, is also worthwhile.

Expression of homologues of the $A$. thaliana vernalization pathway-related genes REDUCED VERNALIZATION RESPONSE 1 (VRN1), REDUCED VERNALIZATION RESPONSE 2 (VRN2) [60], VERNALIZATION 5 (VRN5) [14], EARLY FLOWERING 7 (ELF7), EARLY FLOWERING 8 (ELF8) [18], and FRIGIDA-ESSENTIAL 1 (FES1) [45] was detected. The results showed that only four of the 41 detected genes were down-regulated significantly: the AtVRN5 homologue Glyma07G09800, the two AtVEL1 homologues Glyma13G00920 and Glyma17G07000 in the V4 stage, and one AtELF8 homologue, Glyma09G07980, in the R1 stage. Expression of the remaining genes was not significantly different from WT (Additional file 1: Table S4).

The critical gene in the autonomous pathway in $A$. thaliana is FLOWERING LOCUS C (FLC) [6]. FLC-like genes from plants other than Brassicaceae have not yet been reported, and FLC homologues have not been found in the soybean gene database phytozome server (https://phytozome.jgi.doe.gov/pz/portal.html\#!info?alias $=$ Org_Gmax) or in the Soybase server (https://soybase.org/GlycineBlastPages/). However, the genes that interact with $A$. thaliana $F L C$ have been studied. PHOTOPERIOD-INDEPENDENT EARLY FLOWERING 1 (PIE1) [39], FRIGIDA (FRI) [45], VERNALIZATION INDEPENDENCE (VIPS), FLOWERING TIME CONTROL PROTEIN (FCA), FY [32], FLOWERING LOCUS $D$ (FLD), FVE [4], LUMINIDEPENDENS (LD) and FPA genes [19] all interacted with $F L C$ in A. thaliana and are expressed in both soybean and Arabidopsis. Research has further revealed that these genes are also involved in the regulation of flowering time. Therefore, we investigated the transcription of these genes. A total of 40 FLC-interacting genes were detected in all three stages, and only four genes showed significantly changed expression in the transgenic plants: the AtFVE homologue 
Glyma15G02770, which was down-regulated in the VC stage; the AtFCA homologue Glyma07G36630, which was down-regulated in the V4 stage; and one AtFPA homologue, Glyma13G42061, which was up-regulated in the V4 stage; and the AtFPA homologue Glyma11G13490, which was down-regulated in the R1 stage. The expression of the remaining genes did not show significant differences from WT (Additional file 1: Table S5).

In the GA pathway, one AtRGL3 homologue, Glyma03G37851, was significantly down-regulated in the VC stage compared with WT. The expression levels of nine genes changed significantly in the V4 stage. Glyma20G34260, with homology to AtGAI; Glyma10G02790, Glyma02G17010, and Glyma03G30460, with homology to the GA-related gene OsGID1B (GA INSENSITIVE DWARF1B); and Glyma20G37430, with homology to OsGID1C (GA INSENSITIVE DWARF1B) [3, 37], were up-regulated, and Glyma02G01530, Glyma06G23940 and Glyma10G33380, with homology to AtRGA1, were down-regulated. Moreover, one AtRGL1 homologue, Glyma18G43580, was significantly downregulated in the $\mathrm{R} 1$ stage. The expression of the remaining genes was not significantly different from WT (Additional file 1: Table S6).

\section{MADS-box gene transcription and translation changes in transgenic plants}

MADS-box genes play important roles in flower development, including floral meristem identity, the maintenance and promotion of flower meristem development, and flowering and maturity [49]. Thus, we comprehensively investigated the transcription of MADS-box genes using the RNA-sequencing data. In the three stages (VC, V4 and R1), a total of 132 MADS-box transcripts were detected in WT and transgenic plants (Additional file 1: Table S3). The expression of 34 genes differed significantly between transgenic and WT plants. In addition to GmAGL1, 15 MADS-box genes were up-regulated in one of the three stages, with one gene showing increased expression in two stages, 13 genes showing decreased expression in one stage, and three genes showing decreased expression in two stages. However, only GmAGL1 gene expression was significantly increased in all three periods (Fig. 9a-c). Interestingly, GmAGL1 was the most significantly highly expressed gene among all the genes detected in this study (more than a ten-fold change $(\log 2)$ at the transcript level).

To further confirm this result, Western blotting was performed, revealing higher MADS-box protein contents in SAM from transgenic plants than from WT plants (Fig. 9d).

\section{Discussion}

In this study, GmAGL1 was transferred into the soybean variety 'Jack', and the transgenic plants presented an early flowering phenotype. In addition, the floral features were reduced. Gene insertion site analysis indicated that these phenotypes were caused by the overexpression of GmAGL1, not by the insertion of exogenous fragments that inactivate endogenous genes. Transcriptome sequencing analysis of WT and GmAGL1 overexpression plants indicated that GmAGL1 may promote flowering mainly via the photoperiod pathway. This discovery likely reveals a new function of the $A G L$ gene to promote flowering and maturity.

\section{Roles of the MADS-box gene in flower development and plant maturity}

Genes in the MADS-box family of transcription factors (TFs) play important roles in reproductive growth and development, including flowering and fruit development. For example, the MADS-box genes SOC1 (AGL20) [21], AGAMOUS-LIKE15 (AGL15) and AGAMOUS-LIKE18 (AGL18), along with SVP (AGL22) and AGAMOUSLIKE24 (AGL24) [11], are involved in regulating plant flowering regulation, and, in addition to AP1 (AGL7), the MADS-box genes FUL (AGL8) [23], CAULIFLOWER (CAL, AGL10) [12], SEPALLATA genes [41] and SEEDSTICK (STK, AGL11) [35] also participate in flower identity determination, floral organogenesis, and fruit and seed development. MADS-box genes have been well studied in many plants, but not in soybean, and the specific functions of most genes in this species are unclear.

In this study, GmAGL1-overexpressing transgenic lines presented early flowering, early maturity, and a smaller floral organ, both indoors and in the field, when compared to WT plants. Early in the vegetative stage (VC), with GmAGL1 was up-regulated in transgenic plants, the transcript levels of the floral organ identity MADSbox genes SEP1 and SEP3 were also highly up-regulated in transgenic plants, which may be beneficial to the formation of flowers and the floral organ identity in transgenic plants. The soybean cultivar 'Jack' generally blossomed in the V5-V6 stage. During the flowering preparation period (V4 stage), the MADS-box genes $F T 2 a, S E P 3, A P 1$, and $F U L$, along with the additional flowering regulatory gene $L F Y$, were up-regulated in transgenic plants compared with WT plants, which may be beneficial to the formation of flowers and promote flowering in transgenic plants. In the R1 stage, the reduction of the FT2 $a$ and floral organ identity genes SEP3 and AP1 might have been the major cause of the undersized development of the floral organ in transgenic plants. SHP, AP1, AP3, SEP1, CAL, AG, AGL44, AGL6, $P I$ and $A G L 8$ are $A G$-like MADS-box genes, which have been shown to regulate early flower development [17, 34]. Our previous research has shown that GmAGL1 is a nuclear-localized transcription factor and can interact directly with SEP-like proteins in soybean flowers. It was 


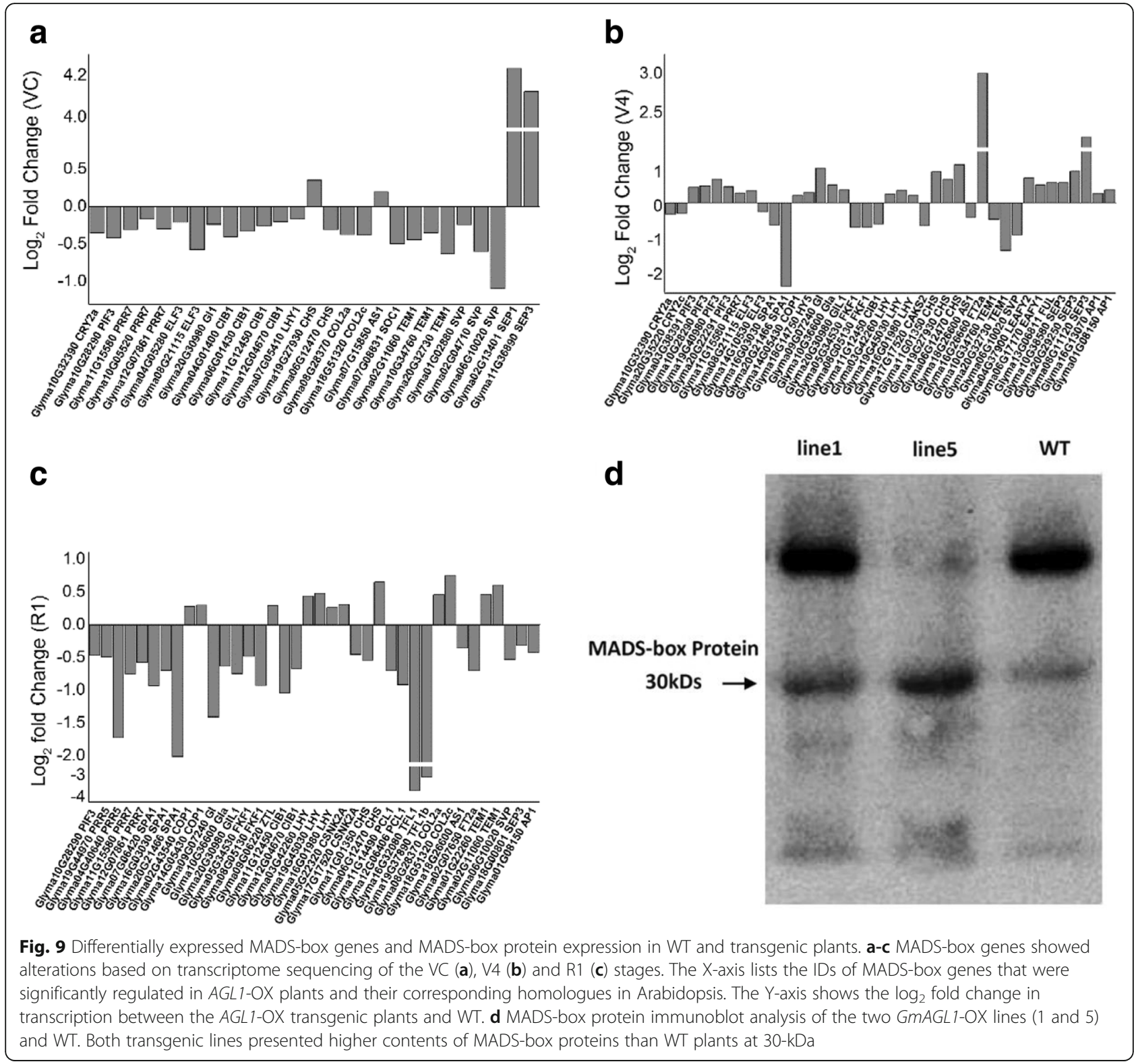

also found to be sufficient to activate the expression of A. thaliana ALC, IND, STK, SEP1, and SEP3 [9]. GmAGL1 may play a role in flower development together with other AG-like MADS-box genes. Thus, while the flower-development-related MADS-box genes $F T 2 a$, SEPs, and AP1 were down-regulated in the R1 stage, this did not affect the ability of the transgenic plants to form complete floral organs with high expression levels of GmAGL1.

The role of the GmAGL1 gene in seed development was also investigated, and, with the exception of precocity, there were no phenotypic differences between the seeds of the transgenic plants and the controls, although the storage protein content was increased in GmAGL1-overexpressing plants.
GmAGL1 promotes flowering mainly via the photoperiod pathway

It is generally accepted that the photoperiod pathway, vernalization pathway, GA-dependent pathway, and autonomous pathway are the four major pathways regulating flowering in $A$. thaliana. Photoperiodicity promotes flowering by combining internal circadian rhythms and external environmental signals. Plant photoreceptors and circadian rhythms integrate external signals and transmit the signal via a central oscillator [15]. Although key photoperiod genes have been studied in many species, research on soybean photoperiod-related genes is not as well established. Thus, A. thaliana and other plants were used as references in this study to identify photoperiodic regulation-related genes in soybean. Gene 
expression between GmAGL1-OX transgenic plants and WT before flowering was compared, and the results showed that the GmAGL1 gene may affect flowering primarily through the photoperiod pathway.

Cryptochromes are the photolyase-related blue-light receptors that regulate plant's responses to light and/or the circadian clock in all major evolutionary lineages [44]. During the transition from the vegetative to reproductive phases, the biological circadian clock genes PRR5, PRR7, SPA1, FKF1, and CIB1 act on the downstream gene CRY2 to affect the flowering process ([38, 56]). Compared with the control, most of the circadian clock genes, such as PRRs, ELF3 and CIB1, exhibited decreased expression in GmAGL1-OX transgenic plants (Figs. 7 and 8a, b). A relationship between the decreased expression of ELF3 and an insensitivity to photoperiod with regard to floral initiation has been characterized in A. thaliana [63]. A similar effect may also occur in soybean, leading to a reduced requirement for a short-day rhythm in transgenic plants to induce reproductive growth. Early flowering of transgenic plants under both short-day and long-day conditions (Fig. 3, Table 2) further confirmed this hypothesis.

Throughout the photoperiod pathway, most genes act similarly to their roles during the blooming of Arabidopsis and tobacco. The flowering-time-promoted genes $\mathrm{CHS}$ [53], COP1 [54], LHY [61], GI[55], FT [22], COL2 [52], and $L F Y$ [7], together with the flowering-identity and floral-organ-development genes SEP1, SEP3, FUL, and $A P 1$ [48], were all highly expressed in transgenic plants compared to WT plants, while the flowering-inhibited genes SPA1 [27], SVP, TFL1 (ShannonandMeeks-Wagner, 1991) were down-regulated and led to the promotion of blooming in transgenic plants. Previous research in our laboratory has shown that GmAGL1 can interact directly with soybean and A. thaliana SEP1 and SEP3 proteins [9], and therefore, high expression levels of GmAGL1 seem to enhance the roles of SEP1 and SEP3 and thus promote flowering. During the transition from vegetative growth to the flowering stage, photoperiodic DEGs formed a complete flowering regulatory pathway that included photoreceptors, the circadian rhythm centre, and downstream regulatory genes (Additional file 1: Figure S4). In addition to the GA-dependent pathway, gene expression in the flowering regulation vernalization pathway and autonomous pathway showed little influence on the entire flowering-regulated pathway. In addition to being a flower-promoting substance, GA is an important signalling hormone that may be involved in other important biological processes [62]. Therefore, we inferred that the photoperiod pathway was the main mechanism by which GmAGL1 promoted flowering.

In conclusion, the photoperiod pathway is the major mechanism by which GmAGL1 promoted soybean flowering. GmAGL1-OX seemed to weaken the demand for strict short-day circadian rhythms in soybeans. Altering the expression patterns of a series of genes associated with optical signals and circadian rhythms, and that further affect the flower morphology, allowed the transgenic plants to undergo a rapid transition to the flowering stage induced by a shorter short-day photoperiod. GA might also play a role in the promotion of flowering.

\section{There is no significant effect of the overexpression of GmAGL1 on seed production}

As the GmAGL1 homologue SHP1/2 has the effect of promotes cracking of pods in A. thaliana [28] and as heterologous expression of GmAGL1 in A. thaliana also increases the number of pods cracked [9], we detected the cracking rate of soybean pods in this experiment. To our surprise, the results showed that neither the cracking rate nor the mature and immature pod phenotype of transgenic plants was significantly different from WT (Table 3; Additional file 3). This phenomenon may be due to differences between plant species and fruit types, suggesting that the function of this gene is not identical in the two plant species.

It is generally accepted that cultivated soybean is selffertile and self-pollinating with an outcrossing rate of less than 4\% [16]. Soybeans do not rely on bright petals and fragrance to attract pollinators. Although the petals of transgenic plants may be smaller and not fully expanded (Fig. $3 \mathrm{a}-\mathrm{C}$ ), this type of undersized development is not a major factor affecting soybean seed production.

GmAGL1-OX transgenic plants exhibited precocious flowering both in the field and indoors under short-day/ long-day conditions and showed prematurity of at least five days in the field compared with the control. These photoperiod responses may be useful for developing short-season cultivars because early maturity provides agricultural producers with more time to harvest and prepare the next crop in the crop rotation for agricultural production. In many crops, seed production is affected by a shortened period of vegetative growth and precocity. In this experiment, the agronomic traits of four generations of transgenic plants in 2015 and 2016 were observed. In 2016, due to the droughts during the drum stage, most of the plants suffered a serious decrease in production. As a result, there were many under-filled seeds, which led to deviations in yield, and oil and protein contents, but there was no significant difference in agronomic traits between transgenic and WT plants (Table 3). We hypothesize that transgenic plants may compensate for the energy required for fruiting organs by reducing consumption by vegetative organs, leading to reduced vegetative growth of stems and leaves (reduced plant height) and slightly reduced growth of genital organs (petals) without affecting normal development. Therefore, 
despite the shortened florescences of transgenic plants, there was no significant reduction in the seed yield of transgenic lines. The finding that the protein content of transgenic plants was increased without affecting the yields indicated that the shortened growth cycle represents an advantageous characteristic of transgenic plants.

\section{Conclusions}

In this work, a MADS-box gene, GmAGL1, was overexpressed in soybean. Phenotypic analysis showed that GmAGL1-overexpressing lines not only resulted in early maturation but also promoted flowering and affected petal development. Further, the role of GmAGL1 was shown to be much more significant in promoting flowering under long-day conditions than under short-day conditions. Transcriptome sequencing analysis of GmAGL1-overexpressing plants indicated that GmAGL1 may promote flowering mainly via the photoperiod pathway. Interestingly, while overexpression of GmAGL1 promotes plant maturity, the results did not show reductions in seed production or oil and protein content.

\section{Methods}

\section{Plant materials}

Seeds of the soybean (Glycine max [L.] Merr.) cultivar 'Jack' were provided by the National Center for Soybean Improvement (Nanjing, China). Soybean seedlings were grown under natural conditions in the isolation plots of Jiangpu Experimental Station, Nanjing Agricultural University, Jiangsu, China. Seeds were sown in late June and harvested in late September to early October from 2013 to 2016. The first generation of GmAGL1-overexpressing (GmAGL1-OX) transgenic plants (T1) grew in 2013, the second generation of transgenic plants (T2) grew in 2014, the third/fourth generation of transgenic plants (T3/T4) grew in 2015, and the fourth/fifth generation of transgenic plants (T4/T5) grew in 2016. T4 seeds were harvested from T3 plants that had been grown in a chamber (CONVIRON AP100, Winnipeg, Canada) under a 14/10-h (day/night) photoperiod at $30 / 20{ }^{\circ} \mathrm{C}$ (day/night) with a relative humidity of $60 \pm 5 \%$ and an average light intensity of $1100 \mu \mathrm{mol} / \mathrm{m}^{2} / \mathrm{s}$ from Nov 2014 to Mar 2015.

All the indoor experimental T2 and T3 plants in this study were cultured in chambers (CONVIRON AP100, Winnipeg, Canada) under a temperature of $30 / 20{ }^{\circ} \mathrm{C}$ (day/night) with a $60 \pm 5 \%$ relative humidity, average light intensity of $1100 \mu \mathrm{mol} / \mathrm{m}^{2} / \mathrm{s}$, normal photoperiod of 14/10 h (light/dark), long-day photoperiod of 16/8 h (light/dark), and short-day photoperiod of 12/12 h (light/dark).

Wild-type (WT) 'Jack' was grown and used as a control for every experiment in this paper.

\section{Generation of transgenic soybean plants}

Full-length GmAGL1 (Gm14g273100) was amplified by PCR using gene-specific primers designed based on sequence information obtained from the NCBI database (Additional file 1: Table S1). PCR conditions were chosen according to the polymerase manufacturer's protocol (Phanta $^{\mathrm{an}}$ Super-Fidelity DNA Polymerase, Vazyme). The GmAGL1 sequence was then cloned into the plant binary vector pmG610021 under the control of the CaMV35S promoter (Additional file 1: Figure S5). The resulting vector containing the glyphosate resistance gene cp4-EPSPE was introduced into Agrobacterium tumefaciens strain EHA105 by electroporation and prepared for transformation via the cotyledon-node method [40]. Shoots germinated from the cotyledon and eventually regenerated a complete plant. The experimental process and the growth of transgenic plants during the different periods are shown in Additional file 4.

Glyphosate-resistant transgenic tissue culture seedlings were confirmed by PCR analysis (primers are listed in Additional file 1: Table S1). Then, Taq-Man probes for cP4-EPSPE were used to detect whether the transgenic plants were homozygous according to the manufacturer's instructions (ABI 7500 Real-Time PCR System, Applied Biosystems, Carlsbad, CA, USA). Gene-specific primers were designed using Primer 5.0 software (Primer-E Ltd., Plymouth, UK), and Taq-Man probes were designed using NTI vector software (Invitrogen Life Technologies). All the primers and probes are described in Additional file 1: Table S1. Homozygous GmAGL1-OX transgenic plants in the T3 and T4 generations were used for further experiments.

\section{Preparation of genomic DNA, RNA and CDNA}

Genomic DNA was extracted from the leaves of WT and GmAGL1-OX transgenic plants using the modified CTAB method [2] and then used for transgene detection by PCR and T-DNA insertion flanking sequence TAILPCR analyses.

Total RNA was extracted using TRIzol reagent (Invitrogen, CA, USA) according to the manufacturer's instructions. Leaves of WT and GmAGL1-OX transgenic plants (T1) were collected to analyse the GmAGL1 expression level, and roots, stems, leaves, flowers, pods, and shoot apical meristem (SAM) of WT and GmAGL1OX transgenic lines (T3) were collected to analyse the tissue expression patterns of GmAGL1. Roots, stems, leaves, and shoot apical meristem (SAM) were collected from 20-day-old plants; flowers and immature pods were collected from 50-day-old plants (10-15 days after flowering); SAMs from VC to R1 stage were collected for the analysis of temporal expression patterns of GmAGL1. All the above tissues were frozen immediately in liquid nitrogen and stored at $-80{ }^{\circ} \mathrm{C}$ until further use. The 
extracted RNAs were then used to prepare cDNA. cDNA was synthesized from $2 \mu \mathrm{g}$ of RNA in a $10 \mu \mathrm{l}$ reaction volume using the Prime Script 1st Strand cDNA Synthesis kit (TaKaRa, Shiga, Japan).

\section{TAIL-PCR and flanking DNA sequence analysis}

T-DNA insertion flanking sequences from transgenic plants were isolated from genomic DNA using the thermal asymmetric interlaced PCR (TAIL-PCR) method as described by Liu and Whittier [29]. The gene-specific primers used for TAIL-PCR were designed using Primer 5.0 software (Primer-E Ltd., Plymouth, UK) and are described in Additional file 1: Table S1.

PCR products were separated by $1 \%$ agarose gel electrophoresis (agarose-L, Nippon Gene Co., Ltd., Toyama, Japan; electrophoresis apparatus), and then, the sequences that were longer than $2 \mathrm{~kb}$ were sequenced by the Sequencing Services Company (Beijing Liuhehuada Genomics Technology Co., Ltd. Shanghai, China). The sequencing data were analysed using the NCBI Blast (http://www. ncbi.nlm.nih.gov/BLAST/), Phytozome (http://phytozom e.jgi.doe.gov/pz/portal.html), and SoyBase (http://www.so ybase.org/GlycineBlastPages/) servers to confirm their genomic locations.

\section{Real-time quantitative PCR}

Real-time quantitative PCR was performed by the SYBR Green method on an ABI 7500 Fast Real-Time PCP system (Applied Biosystems, Carlsbad, CA, USA) using Aceq qPCR SYBR Green Master Mix (Vazyme Biotech Co, Nanjing, China). The following procedure was used for qRT-PCR: 1 cycle at $95^{\circ} \mathrm{C}$ for $5 \mathrm{~min}$, followed by 40 cycles at $95{ }^{\circ} \mathrm{C}$ for $30 \mathrm{~s}, 60{ }^{\circ} \mathrm{C}$ for $30 \mathrm{~s}$, and $72{ }^{\circ} \mathrm{C}$ for $30 \mathrm{~s}$. The gene expression data were analysed using the $2^{-\Delta \Delta \mathrm{Ct}}$ method as described by Livak and Schmittgen [30] (LivakandSchmittgen, 2001). The primers used in these experiments are listed in Additional file 1: Table S1.

\section{Flowering time and flowering phenotype}

Flowering time was measured from sowing to the R1 stage, with the appearance of the first flower at any node of the main stem. In this experiment, five different transgenic lines and one wild-type plant were chosen. In the field, 10 plants were randomly screened to determine the flowering time of each replicate, and three biological replicates were assessed. In the indoor experiment, each line was germinated using 15 seeds per pot under 14/10$\mathrm{h}$ day/night conditions for one week, and then 10 seedlings with a generally consistent growth trend were left for further observations. Each pot was considered one replicate, with a total of three replicates of 10 plants per transgenic line/WT transferred to short-day (12/12-h light/dark) and long-day (16/18-h light/dark) conditions, respectively.
The flowers of WT and GmAGL1-OX transgenic line 5 with the highest expression were selected and dissected to observe the floral organ phenotype. Flowers and young pods of the GmAGL1-OX line 5 and WT in the R3 stage (beginning podding) were chosen and photographs obtained to compare growth.

\section{Investigation of agronomic traits}

To investigate soybean growth and harvesting, eight traits were measured: the plant architecture traits plant height $(\mathrm{PH})$, branch number per plant $(\mathrm{BR})$, node number of the main stem (NM), and cracked pod rate (CR) and the yield components total pods per plant (TP), total seed number per plant (TS), seed yield per plant (SY, measured in g), and kernel weight (SW, measured in $\mathrm{g}$ ). For the measurement of CR, soybean pods from each plant were placed in a paper bag $(10 \times 15 \mathrm{~cm})$ and baked at $37{ }^{\circ} \mathrm{C}$ for four days, and then, the number of cracking pods was counted for the CR measurements. The cracked pod rate per plant was equal to cracking pod number per plant/total pod number per plant $\times 100 \%$ (SR) [13]. The other seven traits were measured as previously described by Zhang et al. [64].

Three replicates of 10 individuals from WT and two GmAGL1-OX transgenic lines were screened for all eight trait measurements.

The protein and oil contents of the soybean seeds were measured by scanning the near infra-red (NIR) absorption spectrum of the seeds using the Grain Analyser (Infratec $^{\text {Tx }} 1241$, FOSS Analytical AB, Denmark). This instrument has an extended wavelength range of 570 $1100 \mathrm{~nm}$ of NIR, and it scans and analyses 10 subsamples of input seeds and provides a recorded reading of the protein and oil contents of soybean seeds according to the instrument built-in computational model: NIR Spectroscopy model S0090711 Soybeans Dry Weight. Triplicate samples of each line were measured.

Experimental data were statistically analysed using SPSS 14.0 software. The t-test was applied to compare transgenic lines and WT.

\section{Protein extraction and western blotting}

A total of $100 \mathrm{mg}$ of SAM from WT and GmAGL1-OX 1 transgenic line 1 and line 5 was used to extract total protein with the ProteoPrep Total Protein Extraction Sample Kit (Sigma-Aldrich, St. Louis, MO, USA) according to the manufacturer's instructions. The MBP-MADS antibody was prepared by Vazyme Biotech Co, Ltd. (Nanjing, Jiangsu, China). The immunogenic recombinant fusion protein MBP-MADS expressed in E. coli had the following amino acid sequence: MGRGRVELKRIENKINRQVTFAKRRNGLLKKAYELSVLC DAEVALIIFSNRGKQYEF.

Western blotting was performed as described by Yamaji and Ma [59]. Briefly, $20 \mu \mathrm{g}$ of total protein was 
separated by $10 \%$ SDS-PAGE at $80 \mathrm{~V}$ for approximately $3 \mathrm{~h}$ and then transferred onto a PVDF membrane. The membrane was blocked with BSA for $2 \mathrm{~h}$ and then hybridized with anti-MADS antiserum for $10 \mathrm{~h}$ (overnight). The protein was detected with BCIP/NBT and placed in the dark for approximately 10 min until colour development occurred.

\section{Transcriptome sequencing and analysis}

cDNA library preparation, sequencing, and preliminary analysis of RNA-sequencing data were performed by Beijing Novogene Institute at Shanghai (Shanghai, China). cDNA libraries were constructed from SAM samples of WT and GmAGL1-OX line 5 at the VC, V4 and R1 stages. The samples were prepared using the Illumina TruSeq RNA sample Prep kit (Illumina, Inc., San Diego, CA, USA) and sequenced on the Illumina HiSeq 2000 platform (Illumina, Inc., San Diego, CA, USA). Gene expression was analysed using the FPKM (expected number of Fragments Per Kilo base of transcript sequence per Millions base pairs sequenced) method [50]. To calculate fold changes, the number of reads for each gene in each library was normalized to the total number of mapped reads for the library, and direct ratios $(\log 2)$ were calculated between the different developmental stages. Transcripts with a significant $P$ value $(<0.05)$ were considered to be differentially expressed. Additionally, KEGG (Kyoto Encyclopedia of Genes and Genomes) pathway analysis of DEGs was performed at http://www.kegg.jp/ for active gene pathways [24].

\section{Additional files}

Additional file 1: Figure S1. Relative GmAGL1 expression in the leaves of the transgenic lines. Figure $\mathbf{S 2}$. Transgene integration sites in five homozygous transgenic lines. Figure S3. Flowers of GmAGL1 overexpression lines in the field. Figure $\mathbf{S 4}$. The overexpression pathway of GMAGL1 promotes flowering in soybean. Figure S5. Vector pmG610021, which includes GmAGL1. Table S1. Primer sequences used in detecting transgenic lines. Table S2. Taq-Man assay results of transgenic plants in the T1 generation. Table S3. Transcripts of all the detected MADS-box genes. Table S4. Transcripts associated with the vernalization pathway. Table S5. Transcripts associated with the autonomous pathway. Table S6. Transcripts associated with the GA-dependent pathway. (PDF $1269 \mathrm{~kb}$ )

Additional file 2: Transcriptome data. (XLSX $10026 \mathrm{~kb})$ Additional file 3: Phenotype of immature pods. (PDF $427 \mathrm{~kb}$ ) Additional file 4: The growth of transgenic plants in different periods. (PDF $560 \mathrm{~kb}$ )

\section{Abbreviations}

AGL: AGAMOUS-LIKE; AP1: APETALA1; CAL: CAULIFLOWER; CIB1: CRYPTOCHROME-INTERACTING BASIC-HELIX-LOOP-HELIX; COP1: CONSTITUTIVE PHOTOMORPHOGENIC1; DAS: Days from sowing; DEGs: Different expression genes; FCA: FLOWERING TIME CONTROL PROTEIN; FKF1: FLAVIN-BINDING KELCH REPEAT F BOx 1; FLC: FLOWERING LOCUS C FT: FLOWERING LOCUS T; FUL: FRUITFULL; GA: Gibberellins acid; GI: GIGANTEA; KEGG: Kyoto Encyclopedia of Genes and Genomes; LD: Long day; LFY: LEAFY; OX: Overexpression; SAM: Shoot apical meristem; SD: Short day; SEP1: SEPALLATA 1; SEP3: SEPALLATA3; SOC1: SUPPRESSOR OF CONSTANS1; SPA1: SUPPRESSOR OF PHYA-105 1; STK: SEEDSTICK; SVP: SHORT VEGETATIVE PHASE; TF: Transcription factors; WT: Wile-type

\section{Acknowledgements}

Not applicable.

\section{Funding}

This work was supported in part by the Key Transgenic Breeding Program of China (2016ZX08004-003,2016ZX08009003-004), National Natural Science Foundation of China $(31,371,644,31,601,324)$ and Jiangsu Collaborative Innovation Center for Modern Crop Production (JCIC-MCP).

\section{Availability of data and materials}

The transcriptome data relating to this article has been added to the additional material.

\section{Authors' contributions}

$X Z$ and DY participated in the design of the study. YC and FH provided the GmAGL1 gene. $X Z$ and HL, HD, WY carried out the molecular genetic studies. $X Z$ and Sujing Wang participated in the phenotypic data collection and performed the statistical analysis. XZ and JW participated in the sequence alignment and performed the computational analysis. XZ and HL participated in drafted the manuscript, took the photos of the plant materials and drew the figures. All authors read and approved the final manuscript.

\section{Ethics approval and consent to participate}

Not applicable.

\section{Consent for publication}

Not applicable.

\section{Competing interests}

The authors declare that they have no competing interests.

\section{Publisher's Note}

Springer Nature remains neutral with regard to jurisdictional claims in published maps and institutional affiliations.

\section{Author details}

'National Key Laboratory of Crop Genetics and Germplasm Enhancement, National Center for Soybean Improvement, Nanjing Agricultural University, Nanjing, Jiangsu 210095, China. ${ }^{2}$ College of Agro-grass-land Science, Nanjing Agricultural University, Nanjing, Jiangsu, China.

Received: 25 May 2017 Accepted: 19 December 2017

Published online: 16 January 2018

\section{References}

1. Ainsworth EA, Yendrek CR, Skoneczka JA, Long SP. Accelerating yield potential in soybean: potential targets for biotechnological improvement. Plant Cell Environ. 2012;35(1):38-52.

2. Allen G, Flores-Vergara M, Krasynanski S, Kumar S, Thompson W. A modified protocol for rapid DNA isolation from plant tissues using cetyltrimethylammonium bromide. Nat Protoc. 2006;1(5):2320-5.

3. Ariizumi T, Murase K, Sun T-p, Steber CM. Proteolysis-independent downregulation of DELLA repression in Arabidopsis by the GIBBERELLIN receptor GIBBERELLIN INSENSITIVE DWARF1. Plant Cell. 2008;20(9):2447-59.

4. Ausín I, Alonso-Blanco C, Jarillo JA, Ruiz-García L, Martínez-Zapater JM. Regulation of flowering time by FVE, a retinoblastoma-associated protein. Nat Genet. 2004;36(2):162-6.

5. Becker A, Theißen G. The major clades of MADS-box genes and their role in the development and evolution of flowering plants. Mol Phylogenet Evol. 2003;29(3):464-89.

6. Blázquez MA, Ahn JH, Weigel D. A thermosensory pathway controlling flowering time in Arabidopsis Thaliana. Nat Genet. 2003;33(2):168-71.

7. Blázquez MA, Soowal LN, Lee I, Weigel D. LEAFY expression and flower initiation in Arabidopsis. Development. 1997;124(19):3835-44.

8. Bluemel M, Dally N, Jung C. Flowering time regulation in crops-what did we learn from Arabidopsis? Curr Opin Biotechnol. 2015;32:121-9. 
9. Chi Y, Wang T, Xu G, Yang H, Zeng X, Shen Y, Yu D, Huang F. GmAGL 1, a MADS-box gene from soybean, is involved in floral organ identity and fruit dehiscence. Front Plant Sci. 2017;8

10. Fan C-M, Wang X, Wang Y-W, Hu R-B, Zhang X-M, Chen J-X, Fu Y-F. Genome-wide expression analysis of soybean MADS genes showing potential function in the seed development. PLoS One. 2013;8(4):e62288.

11. Fernandez DE, Wang C-T, Zheng Y, Adamczyk BJ, Singhal R, Hall PK, Perry SE. The MADS-domain factors AGAMOUS-LIKE15 and AGAMOUS-LIKE18, along with SHORT VEGETATIVE PHASE and AGAMOUS-LIKE24, are necessary to block floral gene expression during the vegetative phase. Plant Physiol. 2014;165(4):1591-603.

12. Ferrándiz C, Gu Q, Martienssen R, Yanofsky MF. Redundant regulation of meristem identity and plant architecture by FRUITFULL, APETALA1 and CAULIFLOWER. Development. 2000;127(4):725-34.

13. Funatsuki $H$, Suzuki $M$, Hirose $A$, Inaba H, Yamada T, Hajika M, Komatsu K, Katayama T, Sayama T, Ishimoto M. Molecular basis of a shattering resistance boosting global dissemination of soybean. Proc Natl Acad Sci. 2014;111(50):17797-802.

14. Greb T, Mylne JS, Crevillen P, Geraldo N, An H, Gendall AR, Dean C. The PHD finger protein VRN5 functions in the epigenetic silencing of Arabidopsis FLC. Curr Biol. 2007;17(1):73-8.

15. Guo H, Yang H, Mockler TC, Lin C. Regulation of flowering time by Arabidopsis photoreceptors. Science. 1998;279(5355):1360-3.

16. Hanson W, Weber CR. Resolution of genetic variability in self-pollinated species with an application to the soybean. Genetics. 1961;46(11):1425.

17. Hayama R, Yokoi S, Tamaki S, Yano M, Shimamoto K. Adaptation of photoperiodic control pathways produces short-day flowering in rice. Nature. 2003;422(6933):719-22.

18. He Y, Doyle MR, Amasino RM. PAF1-complex-mediated histone methylation of FLOWERING LOCUS C chromatin is required for the vernalizationresponsive, winter-annual habit in Arabidopsis. Genes Dev. 2004;18(22):2774-84

19. He Y, Michaels SD, Amasino RM. Regulation of flowering time by histone acetylation in Arabidopsis. Science. 2003;302(5651):1751-4.

20. Huber SC, Rufty TW, Kerr PS. Effect of photoperiod on photosynthate partitioning and diurnal rhythms in sucrose phosphate synthase activity in leaves of soybean (Glycine max L.[Merr.]) and tobacco (Nicotiana Tabacum L). Plant Physiol. 1984:75(4):1080-4.

21. Immink RG, Posé D, Ferrario S, Ott F, Kaufmann K, Valentim FL, De Folter $S$, Van der Wal F, van Dijk AD, Schmid M. Characterization of SOC1's central role in flowering by the identification of its upstream and downstream regulators. Plant Physiol. 2012;160(1):433-49.

22. Jaeger KE, Wigge PA. FT protein acts as a long-range signal in Arabidopsis. Curr Biol. 2007;17(12):1050-4

23. Jia Z, Jiang B, Gao X, Yue Y, Fei Z, Sun H, Wu C, Sun S, Hou W, Han T GmFULa, a FRUITFULL homolog, functions in the flowering and maturation of soybean. Plant Cell Rep. 2015;34(1):121-32.

24. Kanehisa M, Sato Y, Kawashima M, Furumichi M, Tanabe M. KEGG as a reference resource for gene and protein annotation. Nucleic Acids Res. 2016;44(D1):D457-62.

25. Kim MY, Shin JH, Kang YJ, Shim SR, Lee S-H. Divergence of flowering genes in soybean. J Biosci. 2012;37(5):857-70.

26. Kong F, Liu B, Xia Z, Sato S, Kim BM, Watanabe S, Yamada T, Tabata S, Kanazawa A, Harada K. Two coordinately regulated homologs of FLOWERING LOCUS T are involved in the control of photoperiodic flowering in soybean. Plant Physiol. 2010;154(3):1220-31.

27. Laubinger S, Marchal V, Gentilhomme J, Wenkel S, Adrian J, Jang S, Kulajta C, Braun H, Coupland G, Hoecker U. Arabidopsis SPA proteins regulate photoperiodic flowering and interact with the floral inducer CONSTANS to regulate its stability. Development. 2006;133(16):3213-22.

28. Liljegren SJ, Ditta GS, Eshed Y, Savidge B, Bowman JL, Yanofsky MF. SHATTERPROOF MADS-box genes control seed dispersal in Arabidopsis. Nature. 2000;404:766-70

29. Liu Y-G, Whittier RF. Thermal asymmetric interlaced PCR: automatable amplification and sequencing of insert end fragments from P1 and YAC clones for chromosome walking. Genomics. 1995;25(3):674-81.

30. Livak, K.J., and Schmittgen, T.D. (2001). Analysis of relative gene expression data using real-time quantitative PCR and the $2^{-\Delta \Delta C T}$ method. methods 25(4), 402-408

31. Lu, S., Zhao, X., Hu, Y., Liu, S., Nan, H., Li, X., Fang, C., Cao „D., Shi, X., Kong, L., Su, T., Zhang, F., Li, S., Wang, Z., Yuan, X, Cober, ER., Weller, JL., Liu, B., Hou,
X., Tian, Z., Kong, F. (2017). Natural variation at the soybean J locus improves adaptation to the tropics and enhances yield. Nat Genet 49(5):773-779.

32. Marquardt S, Boss P, Hadfield J, Dean C. Additional targets of the Arabidopsis autonomous pathway members, FCA and FY. J Exp Bot. 2006;57(13):3379-86

33. Matsumura H, Liu B, Abe J, Takahashi R. AFLP mapping of soybean maturity gene E4. J Hered. 2008;99(2):193-7.

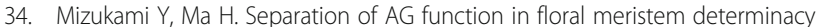
from that in reproductive organ identity by expressing antisense AG RNA Plant Mol Biol. 1995;28(5):767-84.

35. Mizzotti C, Mendes MA, Caporali E, Schnittger A, Kater MM, Battaglia R, Colombo L. The MADS box genes SEEDSTICK and ARABIDOPSIS Bsister play a maternal role in fertilization and seed development. Plant J. 2012;70(3):409-20

36. Mutasa-Göttgens $E$, Hedden P. Gibberellin as a factor in floral regulatory networks. J Experimental Botany erp040. 2009;

37. Nakajima M, Shimada A, Takashi Y, Kim YC, Park SH, Ueguchi-Tanaka M, Suzuki H, Katoh E, luchi S, Kobayashi M. Identification and characterization of Arabidopsis gibberellin receptors. Plant J. 2006:46(5):880-9.

38. Nakamichi N, Kiba T, Henriques R, Mizuno T, Chua N-H, Sakakibara H. PSEUDO-RESPONSE REGULATORS 9, 7, and 5 are transcriptional repressors in the Arabidopsis circadian clock. Plant Cell. 2010;22(3):594-605.

39. Noh Y-S, Amasino RM. PIE1, an ISWI family gene, is required for FLC activation and floral repression in Arabidopsis. Plant Cell. 2003;15(7):1671-82.

40. Olhoft PM, Flagel LE, Donovan CM, Somers DA. Efficient soybean transformation using hygromycin B selection in the cotyledonary-node method. Planta. 2003;216(5):723-35.

41. Pelaz S, Ditta GS, Baumann E, Wisman E, Yanofsky MF. B and C floral organ identity functions require SEPALLATA MADS-box genes. Nature. 2000:405(6783):200-3.

42. Pelaz S, Gustafson-Brown C, Kohalmi SE, Crosby WL, Yanofsky MF. APETALA1 and SEPALLATA3 interact to promote flower development. Plant J. 2001;26(4):385-94

43. Ping J, Liu Y, Sun L, Zhao M, Li Y, She M, Sui Y, Lin F, Liu X, Tang Z. Dt2 is a gain-of-function MADS-domain factor gene that specifies semideterminacy in soybean. Plant Cell. 2014;26(7):2831-42.

44. Sancar A. Structure and function of DNA photolyase and cryptochrome blue-light photoreceptors. Chem Rev. 2003;103(6):2203-38.

45. Schmitz RJ, Hong L, Michaels S, Amasino RM. FRIGIDA-ESSENTIAL 1 interacts genetically with FRIGIDA and FRIGIDA-LIKE 1 to promote the winter-annual habit of Arabidopsis Thaliana. Development. 2005;132(24):5471-8.

46. Shannon S, Meeks-Wagner DR. A mutation in the Arabidopsis TFL1 gene affects inflorescence meristem development. Plant Cell. 1991;3(9):877-92.

47. Shu Y, Yu D, Wang D, Guo D, Guo C. Genome-wide survey and expression analysis of the MADS-box gene family in soybean. Mol Biol Rep. 2013;40(6):3901-11.

48. Simon R, Igeño Ml, Coupland G. Activation of floral meristem identity genes in Arabidopsis. Nature. 1996;384(6604):59.

49. Torti S, Fornara F, Vincent C, Andrés F, Nordström K, Göbel U, Knoll D, Schoof H, Coupland G. Analysis of the Arabidopsis shoot meristem transcriptome during floral transition identifies distinct regulatory patterns and a leucine-rich repeat protein that promotes flowering. Plant Cell. 2012:24(2):444-62

50. Trapnell C, Williams BA, Pertea G, Mortazavi A, Kwan G, Van Baren MJ, Salzberg SL, Wold BJ, Pachter L. Transcript assembly and quantification by RNA-Seq reveals unannotated transcripts and isoform switching during cell differentiation. Nat Biotechnol. 2010;28(5):511-5.

51. Tsubokura, Y., Watanabe, S., Xia, Z., Kanamori, H., Yamagata, H., Kaga, A., Katayose, Y., Abe, J., Ishimoto, M., and Harada, K. (2013). Natural variation in the genes responsible for maturity loci E1, E2, E3 and E4 in soybeanAnnals of botany mct269.

52. Valverde, F. (2011). CONSTANS and the evolutionary origin of photoperiodic timing of floweringJ Experimental botany erq449.

53. Van Der Krol AR, Mur LA, de Lange P, Mol JN, Stuitje AR. Inhibition of flower pigmentation by antisense CHS genes: promoter and minimal sequence requirements for the antisense effect. Plant Mol Biol. 1990;14(4):457-66.

54. Wang H, Ma L-G, Li J-M, Zhao H-Y, Deng XW. Direct interaction of Arabidopsis cryptochromes with COP1 in light control development. Science. 2001;294(5540):154-8.

55. Watanabe $S$, Xia Z, Hideshima R, Tsubokura Y, Sato S, Yamanaka N, Takahashi R, Anai T, Tabata S, Kitamura K. A map-based cloning strategy 
employing a residual heterozygous line reveals that the GIGANTEA gene is involved in soybean maturity and flowering. Genetics. 2011;188(2):395-407.

56. Weidler G, Zur Oven-Krockhaus S, Heunemann M, Orth C, Schleifenbaum F, Harter K, Hoecker U, Batschauer A. Degradation of Arabidopsis CRY2 is regulated by SPA proteins and phytochrome a. Plant Cell. 2012;24(6):2610-23.

57. Wigge PA, Kim MC, Jaeger KE, Busch W, Schmid M, Lohmann JU, Weigel D. Integration of spatial and temporal information during floral induction in Arabidopsis. Science. 2005;309(5737):1056-9.

58. Xia, Z., Watanabe, S., Yamada, T., Tsubokura, Y., Nakashima, H., Zhai, H., Anai, T., Sato, S., Yamazaki, T., and Lü, S. (2012). Positional cloning and characterization reveal the molecular basis for soybean maturity locus $\mathrm{E}$ that regulates photoperiodic flowering. Proceedings National Academy Sciences 109(32), E2155-E2164.

59. Yamaji N, Ma JF. Spatial distribution and temporal variation of the rice silicon transporter Lsi1. Plant Physiol. 2007:143(3):1306-13.

60. Yan L, Loukoianov A, Blechl A, Tranquilli G, Ramakrishna W, SanMiguel P, Bennetzen JL, Echenique V, Dubcovsky J. The wheat VRN2 gene is a flowering repressor down-regulated by vernalization. Science. 2004;303(5664):1640-4.

61. Yon F, Joo Y, Cortés Llorca L, Rothe E, Baldwin IT, Kim SG. Silencing Nicotiana Attenuata LHY and ZTL alters circadian rhythms in flowers. New Phytol. 2016;209(3):1058-66.

62. Yu H, Ito T, Zhao Y, Peng J, Kumar P, Meyerowitz EM. Floral homeotic genes are targets of gibberellin signaling in flower development. Proc Natl Acad Sci U S A. 2004;101(20):7827-32.

63. Zagotta MT, Hicks KA, Jacobs Cl, Young JC, Hangarter RP, Meeks-Wagner DR. The Arabidopsis ELF3 gene regulates vegetative photomorphogenesis and the photoperiodic induction of flowering. Plant J. 1996;10(4):691-702.

64. Zhang H, Hao D, Sitoe HM, Yin Z, Hu Z, Zhang G, Yu D, Singh R. Genetic dissection of the relationship between plant architecture and yield component traits in soybean (Glycine max) by association analysis across multiple environments. Plant Breed. 2015;134(5):564-72.

65. Zheng Q, Zheng Y, Perry SE. Decreased GmAGL15 expression and reduced ethylene synthesis may contribute to reduced somatic embryogenesis in a poorly embryogenic cultivar of Glycine max. Plant Signal Behav. 2013;8(9):e25422

\section{Submit your next manuscript to BioMed Central and we will help you at every step:}

- We accept pre-submission inquiries

- Our selector tool helps you to find the most relevant journal

- We provide round the clock customer support

- Convenient online submission

- Thorough peer review

- Inclusion in PubMed and all major indexing services

- Maximum visibility for your research

Submit your manuscript at www.biomedcentral.com/submit 